\title{
DISCOURSE ANALYSIS AND LANGUAGE TEACHING
}

\author{
Malcolm Coulthard
}

Like other branches of linguistics language teaching has, until recently, bcen concerned with grammatical rather than communicative competence. Wilkins observes that although there have been major changes in the methodology of language teaching over the years the underlying principle has remained the same: "it has been assumed that units of learning should be defined in grammatical terms, although the precise sequence in which they occurred would be influenced by pedagogic considerations," (1972b). Further he suggests that even those courses which encourage dialogue and improvised drama are structured grammatically and the "situations that are created are pedagogic, bearing little resemblance to natural language use."

It is not, of course, that grammatical and communicative syllabuses have different goals; as Widdowson (1979) emphasises, "both types of syllabus recognise that the lcarner's goal should be the ability to communicate" (p.248); rather they differ in their premises about "what nceds to be actually taught for this ability to be acquired" (ibid.). However, it is one thing to onit something deliberately from a syllabus, it is quite another to include items which are actually misleading or wrong; yet, in their concentration on grammar, course books may use interactional structures for what are in reality grammar drills and then students may be taught to produce answers which are grammatically correct but unusual or cven deviant in terms of discourse rules:

$\mathrm{Q}$ : What is this?

A: This ) is a book.

It )

Q: Whare is the typewriter?

A: The typewriter is in the cupboard.

In a methodology which leaves students to deduce rules of use the hidden curriculum can be dangerous. 
Grammatical syllabuses can, of course, have great success in their own terms and those who have followed them conscientiously have usually managed to swim, eventually, when dropped into interactive situations - the crucial question is whether, with all our recently-acquired knowledge about the organisation of interaction and about form-function relationships, we can produce syllabuses which make the task of becoming a successful non-native interactant easier.

An immediate problem is that although Hymes proposed the description of communicative competence as the real goal of linguistics and although it is his work which has fuelled the discussion of communicatively oriented syllabuses, neither he nor his co-workers have been able as yet to provide even a fragment of a description of communicative competence - thus whercas a grammatical syllabus can be based on a well developed description of a native-spcaker's grammar, a communicative syllabus can have no similarly firm foundation.

Following Canale (1983) we can usefully sec communicative competence as being composed of four areas of knowledge and skill: grammatical, sociolinguistic, discourse and strategic competences. Grammatical competence is concerned with "the knowledge and skill required to understand and express the literal meaning of utterances" and as such is the traditional concern of grammatical syllabuses. Sociolinguistic competence is concerned with appropriacy, "both appropriateness of meaning and appropriateness of form", and this includes not simply rules of address and questions of politeness but also selection and formulation of topic and the social significance of indirect speech acts. Discourse competence he sees as concerned with cohesion and coherence in the structure of texts and thus it includes knowledge about the organisation of different speech events and the interpretive rules for relating form to function. Finally strategic competence is "composed of verbal and non-verbal communication strategies" which enable speakers to handle breakdowns in communication and their own lexico-grammatical inadequacies and to enhance the effectiveness of their message.

Given this subdivision of communicative competence we can imagine syllabuses which attempt to teach the components concurrently and other which are organised consecutively. Johns (1978) and Candlin et al. (1978) report interesting Special Purpose Communica- 
tive courses which follow the second stratcgy. These courses were designed for specialists, teachers and doctors respectively, who already have grammatical competence, and some sociolinguistic, discourse and strategic competence in the language and who need to be able to perform like native speakers in their professional roles.

However, such courses based on a detailed analysis of, and intending to improve competence in, one speech event and presupposing a high level of grammatical competence and a supportive second language background are rare. The real test of the approach is how far is it possible to design a communicative syllabus for beginners or false beginners.

Wilkins (1972a, 1976) takes up the challenge and the notional syllabus he proposes is designed to take communicative facts into account "from the beginning without losing sight of grammatical and situational factors" (1976:19). One obvious advantage of a communicative or notional syllabus is that it need not be language specific, but can be designed for a series of culturally related spcech communities, that is communicaties with a large degree of overlap in their norms of interaction. Wilkins, assuming Western Europe to be a fairly homogeneous specch area, asks what are the notions that the European lcarner will expect to bc able to express through the target language (1972a), and sets out to describe them in some detail. Two sets of notions, the semantico-grammatical ones, concerned with 'time', 'space', 'quality', 'matter', 'deixis', and the modal notions of 'modality', 'certainty', 'commitment' are covered in some form by most structural syllabuses, but the categories of communicative function, designed to handle "what speakers do with language" are "the more original part of the framework" (ibid:23).

He observes that "language learning has concentrated... on the use of language to report and describe" but argues that these two functions "are by no means the only ones that are important for the learner of a foreign language" (1972a), and he therefore sets out to classify the functions utterances can perform and also to suggest, for English, the realisations which should be taught first.

He proposes six types of communicative function, "six kinds of thing that we do with language" (1976:44), stressing that he has not restricted himself to "what have come to be called speech acts" 
(ibid:42) - judgement and evaluation, suasion, argument, rational enquiry and exposition, personal emotions and emotive relations. Each function is subclassified, so for instance argument includes information asserted, information sought, information denied, agreement, disagreement and concession and in the 1972 version each subdivision is followed on the lefthand side of the page by "a list of vocabulary items falling within or closely related to its semantic field"; while on the right-hand side of the page are suggested grammatical realisations for students at an early stage of learning. Thus,

$$
\begin{aligned}
& \text { Information sought: } \\
& \text { - request, question, ask. }
\end{aligned}
$$

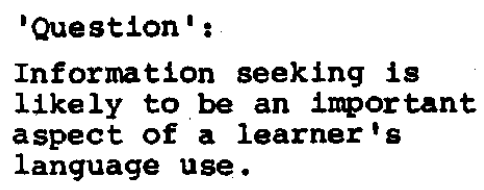

There are many criticisms one can make of Wilkins' framework: some of the categories overlap; some of the realisations sound stilted or odd; and it may not be an accident that there are no suggested realisations for the functions 'sympathy' and 'flattery', but he disarmingly admits the problems and points out himself that it is an 'ad hoc' framework which he expects to be refined and modified in the light of further research. The question we must address is whether such a com- 
municatively based syllabus is in principle to be preferred, because in solving one problem it may create another: if we accept a communicative syllabus in which students are taught at any one time only those grammar items, or even phrases, necessary for the realisation of the function this raises, as Johns (1978) points out,

the question of structuralisation: how can the student be assisted to relate a particular structure 'to the overall framework of the language'. In other words instead of being presented with a coherent grammar of the language and having to construct for himself realisation rules for particular functions, there is a danger that the student may be given little more than a series of guidcbook phrases for greeting, apologising or complaining and have to construct his own grammar.

Wilkins is very much aware of this - he notes that one of the problems that faces the syllabus constructor is to "decide just how much weighting to give to grammatical criteria" (p.65), but other than suggesting a cyclic approach in which students return at different stages of the course, and thus with improving grammatical competence, to the same functions, he doesn't really confront the problem of teaching grammar. Obviously one solution would be to graft the communicative syllabus onto a grammatical one and teach functions as and when their realisations become possible - this is not in fact an unreasonable suggestion because as Wilkins himself points out there is no "intrinsic ordering to the categories" of his syllabus nor any "intrinsic way of linking one unit to the next", but it is not an option that he considers.

Wilkins himself has never published a communicatively structured course, but those who do obviously must make decisions about the sequencing of items and their grammatical realisations.

Jakobovitz \& Gordon (1974) off cr a sketch of the first ten lessons of an intermediate course - interestingly half of the lessons are concerncd with 'describing' and 'reporting', one of the major faults of noncommunicative courses according to Wilkins.

Lesson 1: Grecting and Leave-taking

Lesson 2: Making Requests: Parl 1

Lesson 3: Making Requests: Part 2 
Lesson 4: Extending Invitations

Lesson 5: Making Apologies

Lesson 6: Describing Events: Part 1

Lesson 7: Describing Events: Part 2

Lesson 8: Reporting Events: Part 1

Lesson 9: Reporting Events: Part 2

Lesson 10: Reporting Events: Part 3

For lesson 2 they suggest threc major categories of request:

A. Asking Informational Questions

A1 - that take yes/no answers;

A2 - other

B. Requesting Agreement

B1 - for personal opinion or fecling;

B2 - for proposed action

C. Asking for permission

and for 'Requesting Agreement', they offer the following grammatical structures, two of which sound odd to the British car:

B1. For personal opinion or fecling

(i) $\mathrm{S}+$ don't you think so?

(It's a beautiful day, don't you think so?)

(ii) $\mathrm{S}+$ isn't it?

(It's a beautiful day, isn't it?)

(iii) $\mathrm{S}+$ wouldn't you agree?

(We're much better off here, wouldn't you agree?)

From this outline it is apparent that although the lesson is communicatively labelled 'making requests', it is in fact structurally organised as a lesson on interrogation - polar, wh. and tag-questions. The hidden curriculum is that the three grammatical forms are matched respectively with $\mathrm{A} 1, \mathrm{~A} 2$ and $\mathrm{B} 1$, but tag-questions are only one of the ways to request agreement, others being:

Isn't it a beautiful day

What a bcautiful day

It's a beautiful day

and tag questions can also be used to ask for information. In fact Brazil et al. (1980) would argue that it is intonation choice and not grammati- 
cal form that marks whether it is information or agreement that is being requested.

Abbs et al. (1975), in their introduction to one of the earliest published courses to be functionally rather than grammatically structured, claim that

the learner is taught strategies for handling particular language functions such as identifying people and places, expressing personal tastes, emotions, moods and opinions, giving information, making suggestions, giving advice and so on. The structural contents have been selected as being appropriate to the particular function, rather than as an unrelated series of structures arranged in order of supposed linguistic difficulty.

However, the first few functions are introduced in the following order - with no apparent functionally-based ordering.

Identification

Invitations

Likes and dislikes (1)

Description: People

Description: Places

Impatience

Not knowing

The Past (1)

Surprise and disbelief

It will already be evident that there are major problems in realising a communicative syllabus - it is not simply that there is no logical sequence in which to teach the functions, that as we have seen could be an advantage; it is rather that it is not at all clear what a function is, or how we recognise one. It is all very well to say that functions are concerned with language use but speech act analysis suggests that it is possible to perform several speech acts simultaneously with an indirect utterance; is it also possible to perform several functions simultaneously? Certainly Wilkins' category of personal emotions, which 'express the speaker's emotional reaction to events and people', and Abbs 'impatience' and 'surprise and disbelie? look more like modalities on other functions. 
Secondly there appears to be some confusion between functions like 'invite' and 'warn', which are in a general sense illocutionary and therefore arguably teachable, and 'persuade' and 'incite', which are perlocutionary and thus not really candidates for inclusion in a language course at all. Thirdly the water is further muddied by Wilkins' passing observation that it is "possible for one function to be contained within another" (p.49). Fourthly the problem becomes more acute when we look at the suggested realisations for functions; a large number of Wilkins' examples contain explicit performative verbs, 'I suggest a visit to the zoo', 'I blame John', 'I assert, contend, swear... that I was not responsible for the accident' - but we know that the majority of speech acts are indirect and if we take one of Wilkins' examples for 'blame', 'That was completely unjustified', we realise it could equally well occur as (part of) the functions 'valuation', 'verdiction', 'inducement', 'information asserted', 'disagreement', 'negative emotion' and 'hostility'.

It is not, of course, in the least surprising that there are these problems because they are exactly the ones that have been troubling those involved in the analysis of interaction. However, what is now necessary is for the functional approach to react to and absorb some of the major findings of discourse analysis: that there is organisation above the utterance and some structures like greetings, closings and invitations can be described with some accuracy; that context and position in sequence are vital determinants of functional meanings; that intonation is of crucial significance; and that inferencing is an integral part of interpreting utterances.

\section{Communicative Teaching}

So far we have concentrated on communicative syllabuses, which are essentially lists of functional items, without considering methodology. It is in fact possible to implement a communicative syllabus metalinguistically - Woollard (1984) reports a Malaysian school course for 16-18 year olds based on 88 functional categories and examined and thercfore frequently taught in tcrms of labelling rather than performing. The following cxamples from a Malaysian textbook give some idea of the problem. 
Girl: How can I ever trust you in future?

Boy: On my honour, darling, I won't ever lie to you again.
A. to claim
B. to explain
C. to promise
D. to inform

Father: He's an ungrateful, selfish excuse for a son.

Mother: Perhaps, (sic) he's too busy to come.

He's always so busy with his business deals.
A. to disagrec
B. to defend
C. to advise
D. to claim

(Woollard, p.218)

Of course communicative syllabuses are not intended as the basis for courses on discourse analysis - their main aim is to facilitate and encourage communication in the classroom but the problem is that they tend to encourage a concentration on "components of discourse" and not the "process of its creation" (Widdowson, 1979:249). Paradoxically one docsn't need to follow a Wilkins type communicative syllabus to emphasise communication. In fact Brumfit (1979) suggests that the lasting effect of the communicative movement may be more a shift in methodology than a change in syllabus specification. The traditional methodology, he suggests, was basically.

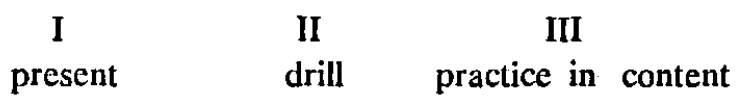

and it was this that Wilkins (1972b) was reacting against when he talked about the interactive situations bcing 'pedagogic, bearing little resemblance to natural language use'. Brumfit (1979) sees the postcommunicative model as 
communicate as

present language items

far as possible shown to be necessary for drill if necessary

with all availeffective communication

able resources

and comments that this is now a student-detcrmined system with the advantage that "what needs to be taught is defined by the failures to communicate at the first stage which thus operates as a diagnosis."

Wilkins suggested that by following a communicative syllabus the learner would "approximate more and more to the language use characteristic of the community whose language he is acquiring" (1976:13), but Brumfit points out that this may be aiming too high, because the learner "is not, usually, aiming to become a member of that community, but mercly to be able to communicate with it" (1979:103). In other words the aim is not to produce somcone who is communicatively competent but rather someone who is a competent communicator, and there is an enormous difference. Thus one of the skills communicative teaching tries to foster is how to cope with limited language resources, a problem which requires excessive use of non-verbal signalling, paraphrase, inferencing, circumlocution, repetition and checking.

It is important at this point to consider what is meant by communication because the label is used for activities which range from drills to simulations, from dialogues to communicative games; in fact, much of what goes on in the forcign language classroom is not genuinely communicative. Apart from those occasions when the teacher is organising the classroom and the lesson, 'open the window/your books', instructing, 'a noun is...' and socialising, 'hello Susan...', all the language used is more or less artificial, because it arises not from a need to use the language but from a requirement by the teacher to produce language. There are, however, degrees of communicativeness and artificiality.

Willis (1983) suggests that all classroom language activities can be seen as one of three kinds, citation, sinulation and replication with only the third being in any real sense communicative. Citation activities are 
formal exercises like repeating, combining and transforming and give rise to sequences like

What is this?

It is a red pen.

What is this?

It is a blue book.

Simulation, including such activitics as discussion and role play, is often regarded as communicative (Sturtridge, 1981), but is not genuinely so. As Willis points out it is only when an activity has an outcome that it is truly communicative - "one of the features of communication is that the communicative decisions we take carry rewards and penalties," whereas in 'role play' there are no penalties - as he observes, in a rolc-playing situation the 'shopkeeper' can treat his customers 'in a surly monosyllabic manner with no risk of his losing their custom' (p.240) and it matters little to the customer if he pays $2 p$ or $£ 2$ a dozen for his eggs; in simulation activities success is again measurcd linguistically.

Replication, Willis suggests, is the closest we can get to genuine communication in the classroom and this is achieved by creating situations in which there is a real need for communication in order to achicve something clse, usually to solve a problem or play a game. In this instance the only artificiality is that the foreign and not the native language is used. Concept 7-9 devised originally for an ESL situation represents one of the earliest examples of such activities; there are now many more, and their advantage is that they involve the student intellectually and affectively, but their very genuineness can be a disadvantage - Fish (personal communication) tells of two Japanese students completing a tangram puzzle well ahead of other students but the only English they used was 'yes' and 'no'. There is thus the danger of students creating a special problem-solving dialect and also of the involvement with the task generating not the intended motivation to learn more communicative stratcgies but rather a growing frustration at having to perform in the forcign language at all.

Brumfit's proposed sequence, attempt to communicate leading to necessary remedial teaching, conceals the very difficult link between 
the two stages - as Willis (ibid, p.253) points out, "many teachers will have great, possibly insurmountable difficulty in diagnosing quickly and effectively the problems students have in their communicative exercises"; as it stands, Brumfit's proposal has the claimed advantage of being student-centered but the disadvantage of being almost impossible to implement. Willis suggests as a modification the sequence

$\begin{array}{ccc}\text { I } & \text { II } & \text { III } \\ \text { Replication } & \text { Citation } & \text { Simulation }\end{array}$

This of course implies a course structured in terms of a careful presentation of activities designed to stimulate the need for certain items which can then be explicitly taught through citation and later practised in simulation situations. Willis conceives the activities in terms of "illocutionary sequences and semantico-grammatical categories" and offers an interesting skctch of a course which takes sequence as the basic communicative unit and sets out to teach students to build up sequences from exchanges and exchanges from moves - different macrofunctions can be slotted into this abstract framework - and decisions about what functions to teach, their sequence and their grammatical realisations are based on insights derived from speech act theory, conversational analysis, discourse analysis and Willis' own research.

An attraclive feature of the Willis-Brumfit proposal is that it doesn't require an out-and-out commitment to structural or communicative syllabuscs. As Willis observes, a replication exercise concerned with distinguishing and matching shapes will naturally lead into citation excrcises concerned with the specific lexis of size and shape and the grammar of nominal group structure. One should also note that whereas replication is a vital part of communicative teaching certain essential aspects of communication, like greetings, closing, invitations and pre-sequences can in fact only be practised through simulation exercises.

It is still carly days to make a final evaluation of the communicative syllabus but as we have seen there are many areas in which it can be improved. There is still a great deal of research to do but we can now see more clearly the areas in which it is needed. Firstly, we need a detailed description of the skills of the competent non-native speaker 
- and even more importantly a ranking of these skills. How do some speakers with limited resources manage to understand and communicate with a great degree of success - in advance of research we can suggest that formulae for agreeing, checking, requesting clarification and repetition, and practice in inferring from context and partial understanding, are essential components of a communicative course.

Secondly there is a great need of contrastive studies - as Richards and Schmidt (1983) point out "so far little attention has been given to the effect of transfer operating at the level of discourse rules." Comparative studies would tell us what stylistic structures and linguistic and sociolinguistic formulations were comparable and therefore less important from a teaching point of view and which were very different. It would be useful to know if greetings and closings work in the same way, if kissing and handshaking is customary or forbidden, if presequences are part of the system, whether the language is one in which the inidirect formulae work in similar ways, whether the politeness system in terms of rulcs of address and situations requiring mitigation are comparable, what topics are usual and what are taboo in interactions between strangers.

Finally, and most importantly, we need some serious research into the teaching/learning process - a disturbingly large number of those who speak several foreign languages see the problem largely in terms of learning vocabulary and structures. Language teachers work in a real and not an ideal world and will always have too litle time - thus we need studies which compare the ultimate communicative performance of students who have followed structural, communicative and a variety of mixed syllabuses; only then will we be able to say for sure whether the best way to teach students to communicate is to teach communicativcly.

- This is a shortened version of Chapter 7 of the second edition of An Introduction to Discourse Analysis, London: Longman, 1985.

\section{BIBLIOGRAPHY}

ABBS, B., AYTON, A. and FRELBAIRN, I. Strategies. London: Longman, 1975.

BRASIl, D.C., COULTIIARD, R.M. and JOHNS, C.M. Discourse Intonation and Language Teaching. London: Longman, 1980. 
BRUMFIT, C.J. "Comunicative Language Teaching: An Educational Perspective". BRUMITI, $C$. and JOIINSON, $K$ (eds.) The Communicative Approacli to Language Teuching, London: O.U.P., 1979. p.183-91.

CANALE, M. "From Communicative Competence to Communictive Language Pedagogy". RICIIARDS, J., and SCHMIDT, $\mathbf{R}$ (eds.) Langunge and Communication, London: Longman, 1983. p.2-27.

CANDLIN; C.N., KIRKWOOD, J.M. and MOORE, H.M. Study Skills in English-Part 1, University of Lancaster, 1978.

JAKOBOBITZ, LA. and GORDON, B. The Context of Foreign Language Teaching. Rowley, Mass.: Newbury House, 1974.

JOINS, T.F. "Seminar Discussion Strategies: Problems and Principles in Role Simulation". University of Birmingham, 1978. Mimeo.

RJClIARDS, J. and Schmidt, R. (eds.). Language and Communication. London: Longman, 1983.

STURTRIDGE, G. "Role Playing and Simulation". JOHNSON K. and MORROW, K. (cds.) Communication in the Classroom. London: Longman, 1981.

WIDDOWSON, II.G. "The Process and Purpose of Reading". WIDDOWSON, H.G. Explorations in Applied Linguistics. Oxford: O.U.P., 1979. p.173-81.

WILKINS, D. "An Investigation Into the Linguistic and Situational Content of the Common Core in a Unit/Credit System". Strasbourg, Council of Europe, 1972a. Mimco.

WILKINS, D. "Grammatical Situational and Notional Syllabuses". Paper Presented to the Third International Congress of Applied Linguistics, Copenhagem, August, 1972b.

WILKINS, D. Notional Syllabuses. London: O.U.P., 1976.

WILKINS, J.D. "The Implications of Discourse Analysis for the Teaching of Oral Communication". Ph.D. thesis, University of Birmingham, 1983.

WOOLLARD, G. "Communicative Functions and Language Teaching With Particular Reference to the Malaysian English Language Syllabus for Forms 4 and 5". M.A. dissertation, University of Birmingham, 1984. 